SOI: $1.1 /$ TAS $\quad$ DOI: $10.15863 /$ TAS International Scientific Journal Theoretical \& Applied Science

p-ISSN: 2308-4944 (print) e-ISSN: 2409-0085 (online)

Year: $2016 \quad$ Issue: 4 Volume: 36

Published: $30.04 .2016 \quad \underline{\text { http://T-Science.org }}$
Sergey Alexandrovich Mishchik Associate Professor, Candidate of Pedagogical Science, Corresponding member of International Academy TAS, Assistant professor Department of Physics, State Maritime University Admiral Ushakov, Russia, sergei_mishik@mail.ru

SECTION 21. Pedagogy. Psychology. Innovation in Education.

\title{
PEDAGOGOMETRIC STRUCTURE STAGES OF FORMATION OF INTEGRITY-SYSTEM CYCLE LIFE OF EDUCATIONAL FACILITIES
}

Abstract: Offered pedagogometric structure stages of formation of integrity-system cycle life of educational facilitiesholistic system of life-through the use of twelve pointed star as the lead Ertsgammy formative processes regarding the psycho-pedagogical activity theory, psycho-pedagogical system analysis and the theory of the formation of mental actions. We consider the holistic development of integrity-system cycle regarding the existence and characteristics of the external and internal structure of the educational space.

Key words: formation stage, pedagogometric, consistency, integrity, stakeholders, personality analysis, star Ertsgammy, educational space.

Language: Russian

Citation: Mishchik SA (2016) PEDAGOGOMETRIC STRUCTURE STAGES OF FORMATION OF INTEGRITY-SYSTEM CYCLE LIFE OF EDUCATIONAL FACILITIES. ISJ Theoretical \& Applied Science, 04 (36): 129-137.

Soi: http://s-o-i.org/1.1/TAS-04-36-21

Doi: crossef http://dx.doi.org/10.15863/TAS.2016.04.36.21

УДК 372.851

\section{ПЕДАГОГОМЕТРИЧЕСКАЯ СТРУКТУРА ЭТАПОВ ФОРМИРОВАНИЯ ЦЕЛОСТНО- СИСТЕМНЫХ ЦИКЛОВ ЖИЗНЕДЕЯТЕЛЬНОСТИ ОБРАЗОВАТЕЛЬНЫХ ОБЪЕКТОВ}

Аннотация: Предложена педагогометрическая структура этапов формирования иелостносистемных ииклов жизнедеятельности образовательных объектов через применение двенадиати конечной звезды Эригаммы в качестве ведущего формообразовательного прочесса относительно психологопедагогической теории деятельности, психолого-педагогического системного анализа и теории формирования умственных действий. Рассматривается цуелостное развитие иелостно-системного ичикла относительно особенностей внешней и внутренней структуры образовательного пространства.

Ключевые слова: формирование, этап, педагогометрика, системность, целостность, субъект деятельность, личность, анализ, звезда Эригаммы, образовательное пространство.

Формирование целостно-системного цикла жизнедеятельности есть многоэтапный процесс. Преобразование внешнего образа мира во внутренний происходит в результате постепенной различно функциональной деятельности, которая отражает базисные рефлекторно-физиологические этапы процесса интериоризации относительно общего процесса познания. Педагогометрический анализ данных процессов позволит проводит плановое моделирование условиями подготовки широкопрофильных специалистов и управление формированием профессиональных качеств личности.
Определение в качестве первого этапа формирования целостно-системной внутренней деятельности процесса ориентации, отражает предметный смысл всей психологопедагогической науки относительно подготовки современных целостно-системных широкопрофильных специалистов, имеющих высший уровень целостно-системной ориентировки в социально-экономических, технических и естественных системах [1].

Целостно-системная ориентационность (ЦСО) есть базисный процесс всей интериоризационной деятельности, которая объединяет все этапы формирования целостно- 
системного цикла жизнедеятельности. ЦСО отражается во всём процессе базисной ориентировки, который отражает особенные характеристики начального целостно-системного ориентационного субъекта. Овладение целостносистемной обобщённой ориентационной деятельностью позволяет начать освоение целостно-системными ориентационными технологическими средствами, которые соответствуют заданной целостно-системной ориентационной технологической деятельности. Эта особенная деятельность направляется на соответствующие целостно-системные ориентационные предметы.

Целостно-системные ориентационные предметы деятельности (ЦСОПД) в результате взаимодействия с целостно-системными ориентационными технологическими средствами через определённую целостно-системную ориентационную технологическую деятельность могут соответствовать заданному целостносистемному ориентационному продукту деятельности, если будет организованная соответствующая целостно-системная ориентационная контрольная деятельность (ЦСОКД). Данный вид деятельности устанавливает условие изоморфизма с выделенным проектным целостно-системным ориентационным продуктом. ЦСОКД имеет соответствующие составляющие относительно её ориентировочного, исполнительного и контрольных компонентов.

Целостно-системный продукт деятельности первую, базисную завершает ориентационности всего целостно-системного цикла жизнедеятельности (ЦСЦЖ). Далее ЦСОПРД выполняет новые предметные условия по самоформированию всего ориентационного ЦСЦЖ. Начинается вторая фаза с целостносистемной ориентационной ритуальной деятельности (ЦСОРД), которая отражает предыдущее единство и будущее развития всего ориентационного ЦСЦЖ. ЦСОРД обладает высшей базисной формой ориентировки, которая определяет профессиональные нормы исполнения и абсолютно точного контроля. Это задаёт условия формирования целостносистемной ориентационной опредмеченной потребности (ЦСООП).

$\begin{array}{crr}\text { ЦСООП } & \text { выполняет } & \text { роль } \\ & \text { средств } & \text { по }\end{array}$
псевдотехнологических средств по самовоспитанию супер-целостно-системнойориентационной личности (СЦСОЛ). ЦСООП задаёт базисные условия по организации целостно-системной ориентационной восходящей деятельности (ЦСОВД), которая формирует целостно-системный ориентационный компаундсубъект (ЦСОКС). ЦСОВД продолжает структурную линию ориентационного, исполнительного и контрольного соответствия относительно базисных соответствий. Сформированный ЦСОКС выполняет роль вторичного предмета деятельности, который устанавливает возникновение целостносистемной ориентационной восходящей деятельности, направленной на воспитание СЦСОЛ - широкопрофильного специалиста.

Каждый элемент ЦСОЦЖ должен отражать результат системного анализа. Поэтому структура ЦСЦЖ ориентационного анализа должен быть представлена как система, с выделением её контуров. В данном случае раскрывается порождающая среда целостносистемной ориентационности, которая является базисным условием развития новых целостносистемных ориентационных схем жизнедеятельности. Это позволяет установить внешние целостно-системные ориентационные свойства по направлениям пространственных, временных, гравитационных, силовых и энергетических характеристик, а также собственно ориентационных, исполнительных и контрольных параметров, которые позволяют создавать многомерные характеристики и параметры ориентировки [2].

Многоуровневый анализ целостносистемного ориентационного цикла жизнедеятельности (ЦСОЦЖ) раскрывает характер её сформированности относительно жизедеятельности, жизнедействия и жизнеоперации, когда целесообразность их существования задаётся соответствующим целостно-системным ориентационным смыслом. Структура каждого уровня ЦСОЦЖ определяется структурными ориентационными элементами и соответствующими ориентационными системообразующими связями. Это устанавливает определённые ориентационные межуровневые целостно-системные отношения, что задаёт форму организации ЦСОЦЖ с ориентационным целостно-системным функциональным смыслом широкопрофильной профессиональной деятельности.

Внутренние характеристики ЦСОЦЖ есть его системные характеристики относительно ориентационной упорядоченности, сложности и упорядоченности. Это позволяет выделить поведение ЦСОЦЖ в статическом и динамических ориентационных поведениях, а также ориентационных переходных статикодинамических режимах. Определяя перспективы развития целостно-системного ориентационного цикла жизнедеятельности необходимо выделять всю структуру предметно-деятельностных ориентационных отношений, которые создают общую схему формирования целостно-системной личности с её широкопрофильным 
профессиональным образом относительно всего целостно-системного

ориентационного интериоризационного и экстериоризационного процессов.

Второй этап формирования целостносистемного цикла жизнедеятельности связан с целостно-системной мотивационностью. Если первый этап, целостно-системная ориентационность, имеет рефлекторное основание, то мотивационность выражает приобретённое качество деятельностного субъекта относительно всего процесса интериоризации. Целостно-системная мотивационность (ЦСМ) есть процесс опережающего, формирующего состояния целостно-системной личности, которая превращается в собственно целостно-системного мотивационного субъекта, который возникает на первом этапе ориентационного формирования целостно-системной жизнедеятельности.

Этап целостно-системной мотивационной жизнедеятельности есть псевдоисполнительный компонент относительно ориентационного и контрольного компонентов различных этапов целостно-системного ряда процессов интериоризации внешнего мира. Целостносистемная мотивационность есть смыслообразующая компонента всех последующих форм целостно-системных циклов жизнедеятельности, которые формируют будущее гиперпространство всех базисных элементов деятельности широкопрофильных специалистов.

Этап целостно-системной мотивационной жизнедеятельности формирует весь целостномотивационный процесс, который начинается с начального базисного целостно-системного мотивационного субъекта деятельности (НБЦСМС), который является порождающим источником всего последующего процесса целостно-системной мотивационности. Через освоение всеобщей целостно-системной мотивационной деятельности (ВЦСМД) и её компонентов: ориентационного, исполнительного и контрольного, возникают условия освоения целостно-системных мотивационных средств деятельности (ЦСМСД), которые являются базисным условием созданием целостносистемной мотивационной технологической деятельности (ЦСМТД).

Целостно-системная мотивационная технологическая деятельность формирует процессы преобразования целостно-системного мотивационного предмета деятельности (ЦСМПД), соблюдая процессы целостносистемных мотивационных ориентировочных, исполнительных и контрольных составляющих. Целостно-системный мотивационный предмет деятельности в результате ЦСМТД и новой целостно-системной мотивационной контрольной деятельности (ЦСМКД) формируется в целостно-системный мотивационный продукт деятельности (ЦСМПРД). Целостно-системная мотивационная контрольная деятельность выполняется в соответствии с выделением ориентировочного, исполнительного и контрольного компонентов, обеспечивающих качество [3].

Целостно-системный мотивационный продукт деятельности определяет начало второй фазы самоформирования целостно-системного мотивационного супер-субъекта деятельности (ЦСМСС). Ц ЦСМПРД выполняет псевдосубъектную роль начала второй фазы самоформирования ЦСМСС, которую выполняет начальный базисный целостно-системный мотивационный субъект деятельности. Через целостно-системную мотивационную ритуальную деятельность (ЦСМРД) происходит формирование целостно-системной мотивационной опредмеченной потребности (ЦСМОП), при этом ЦСМРД развивается при проявление ориентировочного, исполнительного и контрольного компонентов мотивационной ритуальной деятельности базисного процесса.

Целостно-системная мотивационная опредмеченная потребность выполняет псевдосредственную роль второй фазы самоформирования целостно-системного мотивационного супер-субъекта. На предварительном этапе формируется целостносистемный мотивационный компаунд-субъект (ЦСМКС), который возникает в процессе целостно-системной мотивационной восходящей деятельности (ЦСМВД), при этом фиксируются базисные мотивационные ориентационные, исполнительные и контрольные компоненты действия. Целостно-системный мотивационный супер-субъект формируется в процессе организации целостно-системной мотивационной развивающей деятельности (ЦСМРЗД) с определением ориентационных, исполнительных и контрольных компонентов деятельности по формированию целостно-системного мотивационного супер-субъекта деятельности (ЦСМСС).

Bce базисные компоненты целостносистемного мотивационного процесса жизнедеятельности имеют системное представление. На первом этапе раскрывается системная структура мотивационных элементов с основными представлениями. Далее указывается порождающая целостно-системная мотивационная среда, которая в дальнейшем устанавливает внешние, целостно-системные мотивационные характеристики относительно пространственных, временных, гравитационных, силовых, энергетических, ориентационных, 
исполнительных и контрольных параметров. Сложность мотивационных процессов раскрывается через процесс их иерархизации относительно мотивационной жизнедеятельности, жизнедействия и жизнеоперации.

Структура базисного целостно-системного мотивационного компонента представляется через выделение целостно-структурных мотивационных элементов и целостно-системных мотивационных системообразующих связей. При этом фиксируются межуровневые целостносистемные мотивационные отношения. Это приводит к выделению формы организации, системным свойствам (сложности, упорядоченности, разнообразия), статическому и динамическому поведению, прогнозу развития целостно-системных мотивационных компонентов смыслообразующей деятельности специалистов широкого профиля [4].

Третий этап формирования целостносистемного цикла жизнедеятельности связан с целостно-системной визуальностью, которая выражает одну из первых орудийных средств познания окружающего мира. Целостносистемная визуальность - есть одна из высших форм взаимодействия с окружающим миром на основе целостно-системной ориентировочномотивационной деятельности зрительного восприятия действительности. Целостносистемная визуальность выражает особую целостно-системную визуальную жизнедеятельность, которая возникает и формируется на основе инвариантной структуры жизнедеятельности и определяет соответствующий уровень целостно-системной визуальной ориентировки, исполнения и контроля зрительного восприятия.

Целостно-системная

визуальная жизнедеятельность задаётся общим развитием целостно-системного субъекта и, в первую очередь, определяется соответствующими параметрами начального состояния целостносистемного визуального субъекта, который характеризуется визуальными целостными свойствами через пространственные, временные, гравитационные, силовые, энергетические, ориентировочные, исполнительные и контрольные параметры.

Целостно-системный визуальный субъект (ЦСВС) овладевает обобщённой целостносистемной визуальной деятельностью (ЦСВД), которая формируется по базисным характеристикам деятельности, действия и операции в процессе их развития. Это позволяет приступить к освоению целостно-системных визуальных средств деятельности (ЦСВСД), которые характеризуются определёнными энергетическими, силовыми, гравитационными, пространственными, ориентационными, контрольными параметрами, относительными сочетания ии харак также стеристик, которые отражают особенную целостносистемную технологию зрительного восприятия мира относительной общей цели развития целостно-системного субъекта [5].

Возникающая технология целостносистемных визуальных средств деятельности направлена на соответствующие целостносистемные визуальные предметы деятельности (ЦСВПД), которые отражают определённые внешние параметры относительно силовых, гравитационных, энергетических, временных, пространственных, ориентационных, исполнительных и контрольных характеристик, их сочетаний и перестановок зрительного предметного образа. При этом образуется целостно-системная визуальная контрольная деятельность (ЦСВКД), которая в результате базисного структурного цикла ориентировка, исполнение и контроль устанавливает изоморфное соответствие между зрительными образами и прообразами визуальной предметности.

Результатом целостно-системной визуальной контрольной деятельности является целостно-системный визуальный продукт деятельности (ЦСВПРД), который отражает первый результат формирования нового целостно-системного визуального суперсубъекта. ЦСВПРД является многофункциональным субъектно-средственным предметом саморазвития целостно-системного визуального субъекта. Первой деятельной формой активации ЦСВПРД является целостносистемная визуальная ритуальная деятельность (ЦСВРД), которая отражает особенные формы проявления активности ориентировочного, исполнительного и контрольного характера по установлению целостно-системной опредмеченной визуальной потребности (ЦСОВП).

Целостно-системная опредмеченная визуальная потребность является псевдосредством новой формы саморазвития целостно-системного визуального субъекта. ЦСОВП вызывает кардинальную форму целостно-системной визуальной восходящей деятельности (ЦСВВД), которая в процессе реализации базисных ориентировочных, исполнительных и контрольных составляющих компонентов зрительного преобразования внешнего мира формирует целостно-системный визуальный компаунд-субъект (ЦСВКС). Он определяется как псевдо предмет самоформирования целостно-системного визуального супер-субъекта деятельности 
(ЦСВССД). Процесс перехода к высшей форме визуальных субъектных отношений происходит через целостно-системную визуальную развивающую деятельность (ЦСВРД), которая формирует ЦСВССД в результате выполнения базисных ориентировочны, исполнительных и контрольных зрительных форм деятельности. Возникающий целостно-системный визуальный супер-субъект деятельности отражает весь смыслообразующий компонент всего процесса целостно-системной визуальной жизнедеятельности (ЦСВЖД).

Каждый элемент целостно-системной визуальной жизнедеятельности имеет системное представление. На первом этапе системного анализа устанавливаются общие контуры системного представления с определением характеристик порождающей среды, внешних свойств элементов, уровней анализа, их структуры, формы организации, поведения и начальные прогнозы развития. В дальнейшем происходит раскрытие детализаций процесса целостно-системной визуализации, как особой формы жизнедеятельности и этапа формирования абсолютной целостно-системной визуализированной супер-личности, которая способна на данном этапе интериоризационного развития устанавливать пространственные, силовые, энергетические, временные, гравитационные, ориентировочные, исполнительные и контрольные параметры зрительного восприятия, относительно структурных и системообразующих связей визуализации образа внешнего мира, а также определять сложность, упорядоченность и разнообразие зрительного ряда развития в условиях статического и динамического зрительного ощущения относительно перспектив саморазвития субъекта [6].

Четвёртый этап формирования целостносистемного цикла жизнедеятельности определяется целостно-системной акустичностью (ЦСА), которая устанавливает дальнейшее освоение орудийных средств познания звукового образа мира. Целостно-системная акустичность выражает высшую форму взаимодействия с окружающим миром на основе целостносистемной ориентировочно-мотивационнойвизуальной деятельности звукового восприятия действительности. Целостно-системная акустичность выражает определённую целостносистемную звуковую жизнедеятельность, которая возникает и формируется на основе инвариантнообобщённой структуры жизнедеятельности и устанавливает соответствующий уровень целостно-системной акустичной ориентировки, исполнения и контроля восприятия звуковой системы мира.
Целостно-системная акустическая жизнедеятельность (ЦСАЖ) начинается с выражения собственного акустического «Я» начального целостно-системного акустического субъекта (НЦСАС), который обладает набором целостных акустических характеристик относительно их внешних звуковых инвариантных образов, устанавливающих звуковой ряд параметров.

К таким внешним акустическим характеристикам относятся пространственные, временные, гравитационные, силовые, энергетические, ориентационные, исполнительные и контрольные величины, определяющие начальные акустические образы. Процесс реализации начальных акустических возможностей начинает реализовываться через освоение всеобщей целостно-системной акустической деятельности (ВЦСАД). Этот вид деятельности отражает базисные целостносистемные акустические параметры относительно выделенной ориентировочной, исполнительной и контрольной составляющих акустической деятельности в решении полного ряда акустических познавательных учебных и профессиональных задач специалиста широкого профиля [7].

Всеобщая целостно-системная акустическая деятельность позволяет начать освоение целостно-системных акустических технологических средств деятельности (ЦСАТСД), которые выражают исполнительный акустический образ начального акустического целостно-системного субъекта. ЦСАТСД отражают те будущие характеристики звукового ряда, которые необходимо сформировать в процессе специально организованной целостносистемной акустической технологической деятельности (ЦСАТД). Данная деятельность выражает последовательность действий акустического системного анализа, который отражает поведение ЦСАТСД в определённых технологических условия относительно ориентировочной, исполнительной и контрольной фазы.

ЦСАТД направлена на целостно-системный акустический предмет деятельности (ЦСАПРД), который отражает предметные условия акустического формирования ЦСАС. Этот акустический предмет обладает предварительными целостно-системными акустическими характеристиками, которые необходимо сформировать в заданных условиях жизнедеятельности относительно внешних, целостных характеристик. При этом возникает целостно-системная акустическая контрольная деятельность (ЦСАКД), которая направлена на установление соответствия между образом и будущим акустическим прообразом цели 
жизнедеятельности самоформирования на первой фазе целостно-системного акустического супер-субъекта в форме акустического продукта деятельности.

Возникающий целостно-системный акустический продукт деятельности (ЦСАПРДД) устанавливает предметно-субъектные условия формирования нового типа акустического субъекта с минимаксными и максоминными параметрами. ЦСАПРДД обладает реальными акустическими характеристиками, которые имею возможность дальнейшего развития через целостно-системные акустические параметры относительно сложности, разнообразия и упорядоченности их возможностей. Процесс контрастного выражения параметров организуется в результате формирования целостно-системной акустической ритуальной деятельности (ЦСАРД), которая выполняет псевдоориентировочную основу самоформирования целостно-системного акустического супер-субъекта.

Результатом ЦСАРД является целостносистемная акустическая опредмеченная потребность (ЦСАОП), которая выполняет роль псевдосредств формирования целостносистемного акустического супер-субъекта (ЦСАСС). ЦСАОП через восходящую целостносистемную акустическую деятельность (ЦСАВД) начинает формировать в процессе заданных акустических характеристик ориентировки, исполнения и контроля целостно-системный акустический компаунд-субъект (ЦСАКС). При этом ЦСАКС можно представить в виде целостно-системных акустических псевдосредств самоформирования ЦСАСС, который в окончательном виде возникает при организации целостно-системной акустической развивающей деятельности (ЦСАРЗД).

ЦСАРЗД формирует процесс самовоспитания ЦСАСС по общим законам представления акустической развивающей ориентировки, исполнения и контроля. Целостносистемная акустическая развивающая деятельность выполняет базисную контрольную акустическую деятельность, когда возникают условия смыслообразования акустического образа супер-субъекта. Полное представление ЦСАСС организуется через акустический системный анализ, когда акустический образ представлен как система, отражённая в порождающем ряде целостно-системной акустической среды, выраженной через многоуровневый фонетический образ в многочисленном ряде форм акустической организации, системных свойств, статического и динамического поведения мира акустики.

Пятый этап формирования целостносистемного цикла жизнедеятельности определяется

целостно-системной колориметричностью (ЦСК), которая устанавливает дальнейшее освоение орудийных средств познания цветового образа мира. Целостно-системная колориметричность выражает высшую форму взаимодействия с окружающим миром на основе целостносистемной ориентировочно-мотивационнойвизуальной-колористической деятельности цветового восприятия действительности. Целостно-системная колористичность выражает определённую целостно-системную цветовую жизнедеятельность, которая возникает и формируется на основе инвариантно-обобщённой структуры жизнедеятельности и устанавливает соответствующий уровень целостно-системной цветовой ориентировки, исполнения и контроля восприятия цветовой системы мира.

Целостно-системная колористическая жизнедеятельность (ЦСКЖ) начинается с выражения собственного колористического «Я» начального целостно-системного колористического субъекта (НЦСКС), который обладает набором целостных колористических характеристик относительно их внешних цветовых инвариантных образов, устанавливающих цветовой ряд параметров.

К таким внешним колористическим характеристикам относятся пространственные, временные, гравитационные, силовые, энергетические, ориентационные, исполнительные и контрольные величины, определяющие начальные колористические образы. Процесс реализации начальных колористических возможностей начинает реализовываться через освоение всеобщей целостно-системной колористической деятельности (ВЦСКД). Всеобщая целостносистемная колористическая деятельность позволяет начать освоение целостно-системных колористических технологических средств деятельности (ЦСКТСД), которые выражают исполнительный колористический образ начального колористического целостносистемного субъекта. ЦСКТСД отражают те будущие характеристики цветового ряда, которые необходимо сформировать в процессе специально организованной целостно-системной колористической технологической деятельности (ЦСКТД).

ЦСКТД направлена на целостно-системный колористический предмет деятельности (ЦСКПРД), который отражает предметные условия колористического формирования ЦСКС. Этот колористический предмет обладает предварительными целостно-системными колористическими характеристиками, которые необходимо сформировать в заданных условиях жизнедеятельности относительно внешних, 
целостных характеристик. При этом возникает целостно-системная колористическая контрольная деятельность (ЦСККД), которая направлена на установление соответствия между образом и будущим колористическим прообразом цели жизнедеятельности на первой фазе самоформирования целостно-системного колористического супер-субъекта в форме колористического продукта деятельности [8].

Возникающий целостно-системный колористический продукт деятельности (ЦСКПРДД) устанавливает предметносубъектные условия формирования нового типа колористического субъекта с минимаксными и максоминными параметрами. ЦСКПРДД обладает реальными колористическими характеристиками, которые имею возможность дальнейшего развития через целостно-системные колористические параметры относительно сложности, разнообразия и упорядоченности их возможностей. Процесс контрастного выражения параметров организуется в результате формирования целостно-системной колористической ритуальной деятельности (ЦСКРД), которая выполняет псевдоориентировочную основу самоформирования целостно-системного колористического супер-субъекта.

Результатом ЦСКРД является целостносистемная колористическая опредмеченная потребность (ЦСКОП), которая выполняет роль псевдосредств формирования целостносистемного колористического супер-субъекта (ЦСКСС). ЦСКОП через восходящую целостносистемную колористическую деятельность (ЦСКВД) начинает формировать в процессе заданных колористических характеристик ориентировки, исполнения и контроля целостносистемный колористический компаунд-субъект (ЦСККС). При этом ЦСККС можно представить в виде целостно-системных колористических псевдосредств самоформирования ЦСКСС, который в окончательном виде возникает при организации колористической развивающей деятельности (ЦСКРЗД).

ЦСКРЗД формирует процесс самовоспитания ЦСКСС по общим законам представления колористической развивающей ориентировки, исполнения и контроля. Целостносистемная колористическая развивающая деятельность выполняет базисную контрольную акустическую деятельность, когда возникают условия смыслообразования колористического образа супер-субъекта. Полное представление ЦСКСС организуется через колористический системный анализ, когда колористический образ представлен как система, отражённая в порождающем ряде целостно-системной колористической среды, выраженной через многоуровневый колористический образ в многочисленном ряде форм колористической организации, системных свойств, статического и динамического поведения мира колористики [9].

Шестой этап формирования целостносистемного цикла жизнедеятельности определяется целостно-системной термодинамичностью (ЦСТ), которая устанавливает дальнейшее освоение орудийных средств познания теплового образа мира. Целостно-системная термодинамичность выражает высшую форму взаимодействия с окружающим миром на основе целостносистемной мультирефлексивной деятельности теплового восприятия действительности. Целостно-системная термодинамичность выражает определённую целостно-системную тепловую жизнедеятельность, которая возникает и формируется на основе инвариантнообобщённой структуры жизнедеятельности и устанавливает соответствующий уровень целостно-системной тепловой ориентировки, исполнения и контроля восприятия тепловой системы мира.

Целостно-системная термодинамическая жизнедеятельность (ЦСТЖ) начинается с выражения собственного термодинамического «Я» начального целостно-системного термодинамического субъекта (НЦСТС), который обладает набором целостных термодинамических характеристик относительно их внешних тепловых инвариантных образов, устанавливающих тепловой ряд параметров.

К таким внешним термодинамическим характеристикам относятся пространственные, временные, гравитационные, силовые, энергетические, ориентационные, исполнительные и контрольные величины, определяющие начальные термодинамические образы. Процесс реализации начальных термодинамических возможностей начинает реализовываться через освоение всеобщей целостно-системной термодинамической деятельности (ВЦСТД). Всеобщая целостносистемная термодинамическая деятельность позволяет начать освоение целостно-системных термодинамических технологических средств деятельности (ЦСТТСД), которые выражают исполнительный термодинамический образ начального термодинамического целостносистемного субъекта. ЦСТТСД отражают те будущие характеристики теплового ряда, которые необходимо сформировать в процессе специально организованной целостно-системной термодинамической технологической деятельности (ЦСТТД). Данная деятельность выражает последовательность действий термодинамического системного анализа, 
который отражает поведение ЦСТТСД в определённых технологических условиях относительно ориентировочной, исполнительной и контрольной фазы.

ЦСТТД направлена на целостно-системный термодинамический предмет деятельности (ЦСТПРД), который отражает предметные условия термодинамического формирования ЦСТС. Этот термодинамический предмет обладает предварительными целостносистемными термодинамическими характеристиками, которые необходимо сформировать в заданных условиях жизнедеятельности относительно внешних, целостных характеристик. При этом возникает целостно-системная термодинамическая контрольная деятельность (ЦСТКД), которая направлена на установление соответствия между образом и будущим термодинамическим прообразом цели жизнедеятельности на первой фазе самоформирования целостно-системного термодинамического супер-субъекта в форме термодинамического продукта деятельности.

Возникающий целостно-системный термодинамический продукт деятельности (ЦСТПРДД) устанавливает предметносубъектные условия формирования нового типа термодинамического субъекта с минимаксными и максоминными параметрами. Процесс контрастного выражения параметров организуется в результате формирования целостно-системной термодинамической ритуальной деятельности (ЦСТРД), которая выполняет псевдоориентировочную основу самоформирования целостно-системного термодинамического супер-субъекта.

Результатом ЦСТРД является целостносистемная термодинамическая опредмеченная потребность (ЦСТОП), которая выполняет роль псевдосредств формирования целостносистемного термодинамического супер-субъекта
(ЦСТСС). ЦСТОП через восходящую целостносистемную термодинамическую деятельность (ЦСТВД) начинает формировать в процессе заданных термодинамических характеристик ориентировки, исполнения и контроля целостносистемный термодинамический компаундсубъект (ЦСТКС). При этом ЦСТКС можно представить в виде целостно-системных термодинамических псевдосредств самоформирования ЦСТСС, который в окончательном виде возникает при организации целостно-системной термодинамической развивающей деятельности (ЦСТРЗД) [10].

$$
\text { ЦСТРЗД формирует процесс }
$$

самовоспитания ЦСТСС по общим законам представления термодинамической развивающей ориентировки, исполнения и контроля. Целостносистемная термодинамическая развивающая деятельность выполняет базисную контрольную акустическую деятельность, когда возникают условия смыслообразования термодинамического образа супер-субъекта. Полное представление ЦСТСС организуется через термодинамический системный анализ, когда термодинамический образ представлен как система, отражённая в порождающем ряде целостно-системной термодинамической среды, выраженной через многоуровневый термодинамический образ в многочисленном ряде форм термодинамической организации, системных свойств, статического и динамического поведения мира термодинамистики.

Выделенные первые шесть этапов формирования целостно-системной жизнедеятельности определяют базисную педагогометрическую структуру этапов формирования целостно-системных циклов жизнедеятельности относительно образовательных объектов.

\section{References:}

1. Mishchik SA (2014) Pedagogometrika and mathematical modeling educational activity. Materialy Mezhdunarodnoy nauchnoy konferenctsii "Modern mathematics in science" - 30.06.2014. ISJ Theoretical \&Applied Science 6(14): 54-56 Caracas, Venezuela. doi: http://dx.doi.org/10.15863/TAS.2014.06.14.10

2. Mishchik SA (2014) Simulation training activity methods of mathematical logic. Materialy Mezhdunarodnoy nauchnoy konferenctsii "Eurapean Science and
Education" - 30.07.2014. ISJ Theoretical \&Applied Science 6(15): 72-74 Marseille, France. doi: http://dx.doi.org/10.15863/TAS.2014.07.15.13

3. Mishchik SA (2014) Mathematical modeling system integrity-cycle of life activity - first goal pedagogometriki. Materialy Mezhdunarodnoy nauchnoy konferenctsii "European Applied Sciences" - 30.08.2014. ISJ Theoretical \&Applied Science 7(16): 77-79. 


\begin{tabular}{l|lrl|l|ll} 
& ISRA (India) & $=\mathbf{1 . 3 4 4}$ & SIS (USA) & $=\mathbf{0 . 9 1 2}$ & ICV (Poland) & $=\mathbf{6 . 6 3 0}$ \\
Impact Factor: & ISI (Dubai, UAE) $=\mathbf{0 . 8 2 9}$ & PUHL (Russia) $=\mathbf{0 . 2 3 4}$ & PIF (India) & $=\mathbf{1 . 9 4 0}$ \\
& GIF (Australia) & $\mathbf{0 . 5 6 4}$ & ESJI (KZ) & $=\mathbf{1 . 0 4 2}$ & IBI (India) & $=\mathbf{4 . 2 6 0}$ \\
& JIF & $\mathbf{1 . 5 0 0}$ & SJIF (Morocco) & $=\mathbf{2 . 0 3 1}$ & & \\
\hline
\end{tabular}

Aix-en-Provence, France. doi: http://dx.doi.org/10.15863/TAS.2014.08.16.13

4. Mishchik SA (2014) Mathematical modeling system integrity-curricular activities - the second problem pedagogometriki. Materialy Mezhdunarodnoy nauchnoy konferenctsii "European Innovation" - 30.09.2014. ISJ Theoretical \&Applied Science 9(17): 126-128 Martigues, France. doi: http://dx.doi.org/10.15863/TAS.2014.09.17.21

5. Mishchik SA (2014) Mathematical modeling holistic-systemic communicative activity - the third task pedagogometriki. Materialy Mezhdunarodnoy nauchnoy konferenctsii "European Scientific Achievements" 30.10.2014. ISJ Theoretical \&Applied Science 10(18): 45-47 Brighton, UK. doi: http://dx.doi.org/10.15863/TAS.2014.10.18.11

6. Mishchik SA (2014) Mathematical modeling integrity - system performance subject - fourth task pedagogometriki. Materialy Mezhdunarodnoy nauchnoy konferenctsii "Eurapean Science and Technology" 30.11.2014. ISJ Theoretical \&Applied Science 11(19): 51-54 Southampton, UK. doi: http://dx.doi.org/10.15863/TAS.2014.11.19.10

7. Mishchik SA (2015) Pedagogometrik - science and academic subject. Materialy Mezhdunarodnoy nauchnoy konferenctsii
"European Technology in Science" 28.02.2015. ISJ Theoretical \& Applied Science 02 (22): 103-106 Malmö, Sweden. doi: http://dx.doi.org/10.15863/TAS.2015.02.22.17

8. Tokmazov GV (2014) Matematicheskoe modelirovanie $\mathrm{v}$ uchebno-professional'noy deyatel'nosti. Materialy Mezhdunarodnoy nauchnoy konferentsii «Modern mathematics in science» - 30.06.2014. ISJ Theoretical \& Applied Science 6(14): 44-46. - Caracas, Venezuela. doi: http://dx.doi.org/10.15863/TAS.2014.06.14.8

9. Tokmazov GV (2014) Analysis says study skills in the study of mathematics, Materialy Mezhdunarodnoy nauchnoy konferenctsii "Eurapean Science and Education" 30.07.2014. ISJ Theoretical \&Applied Science 6(15): 72-74 Marseille, France. doi: http://dx.doi.org/10.15863/TAS.2014.06.14.8

10. Tokmazov GV (2014) Mathematical modeling research skills in educational activity methods of probability theory. Materialy Mezhdunarodnoy nauchnoy konferenctsii "Eurapean Science and Technology" 30.11.2014. ISJ Theoretical \&Applied Science 11(20): 66-69 Southampton, United Kingdom. doi:

http://dx.doi.org/10.15863/TAS.2014.11.19.13 